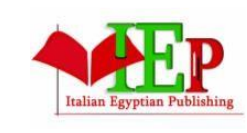

ISSN: $2735-4806$
INTERNATIONAL JOURNAL OF

ARTIFICIAL INTELLIGENCE AND EMERGING

TECHNOLOGY

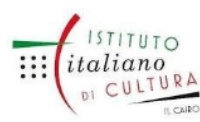

www.egyptfuture.org/ojs/

VOLUME 1, ISSUE $1,2018,8-10$.

\title{
AUTOMATIC OPERATING SYSTEM FOR THE OFFICE'S BUILDINGS: COMPARATIVE STUDY
}

\author{
Mennatallah Gamal QASEM, "Yasmine Sabri HEGAZY, Hussein Sabri EL-SHENNAWY
}

The Architectural Department, Faculty of Engineering, Zagazig University, Egypt

\begin{abstract}
The building automation system is defined as the operation of various building systems (e.g. lighting, air conditioning, firefighting etc.) without the need for human intervention (or minimal human intervention) to control and monitor the internal environment to ensure that it operates at the optimum level. Building automation system provides the internal environment with several features including increased user comfort, reduced operating and maintenance costs, improved control system efficiency and reduced power consumption, as well as increased user productivity. This research studies the effect of the automation system on the performance of engineering firms in Egypt. The problem arises from the absence of periodic evaluation of operating systems, which leads to deterioration of its level. The post-occupancy evaluation (as a tool to measure the success of the design objectives of the building after its construction) is applied to office buildings. The evaluation provides a way to collect data about the building and has a great importance to all participants in the building's life cycle; it includes several measures such as thermal comfort, lighting, acoustics, Sick Building Syndrome (SBS) etc. The objective of the evaluation is to improve the quality of the design, the building and the administration, and thus enhance the building environment. The research used a combined strategy included the descriptive study approach with a comparative analysis of the impact of the automation system using post-occupancy evaluation by conducting 72 questionnaires for two office buildings users, the questionnaire aspects included: indoor environmental quality, Productivity in work and architectural design. The research concluded that levels of satisfaction in non-automated buildings are moderate, compared with higher levels of satisfaction in the automated buildings. The research also concluded that when using fully automated building, the possibility of personal control at different levels of the building must be considered.
\end{abstract}

Keywords

Building Automation System, Office Buildings, Post-Occupancy Evaluation, User Satisfaction, Indoor Environmental Quality. 


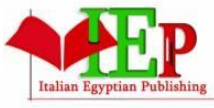

ISSN: $2735-4806$
INTERNATIONAL JOURNAL OF

ARTIFICIAL INTELLIGENCE AND EMERGING

TECHNOLOGY

VOLUME 1, ISSUE $1,2018,8-10$.

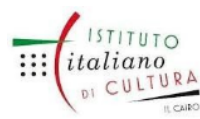

www.egyptfuture.org/ojs/

\section{INTRODUCTION}

The research used a combined strategy included the descriptive study approach with a comparative analysis of the impact of the automation system using post-occupancy evaluation questionnaire. Research materials are post-occupancy evaluation questionnaire for building's users. The survey was conducted electronically and in paper. The questionnaire consists of 70 questions, mostly scale questions (Likert).

The questionnaire is divided into four main parts: the first part discusses indoor environmental quality which includes visual comfort, thermal comfort, indoor air quality and acoustics. The second discusses part user satisfaction which includes personal control and response to problems. The third part is the work productivity, and the final part is architectural design, and it includes questions about architectural renovation, security, access, and technology used.

\section{Research Objective}

Evaluating the efficiency of automated office buildings using post-occupancy evaluation and studying its impact on users and their satisfaction in Egypt.

\section{Research Problem}

The performance of buildings decreases after occupancy due to the absence of periodic evaluation (non-technical), which ensures continuity of operation of the system with the desired efficiency (especially in Egypt).

\section{CONCLUSION}

By reviewing the results, we find that the automated operating system has succeeded in raising users' satisfaction and comfort comparing with other traditional buildings. It also helped create an internal environment that raises the performance of users compared to another building that does not depend on the system. The biggest problem that faced the system in the case of the study was the failure to introduce fresh air into the air conditioning system, in addition to poor personal control, which led to a percentage of dissatisfaction.

The research recommends the application of the automated operating system in engineering office buildings with a higher level of personal control for users compared to other buildings that may not need this, as the main purpose of the workplace is to provide an appropriate environment that raises the level of employee performance, which increases the productivity Company / office. The research also recommends the necessity of using the post- work evaluation periodically, to find out the problems facing the building and its users and to try to reach the most efficient solutions.

References: 


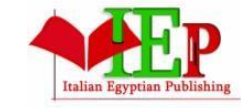

ISSN: $2735-4806$

\section{INTERNATIONAL JOURNAL OF \\ ARTIFICIAL INTELLIGENCE AND EMERGING \\ TECHNOLOGY}

VOLUME 1, ISSUE $1,2018,8-10$.

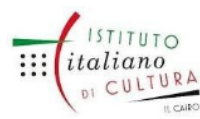

www.egyptfuture.org/ojs/

- $\quad$ Amirante, M. Isabella \& Burattini, Ernesto. (1996). Automatic procedures for bio-climatic control. In Education for Practice. Proceedings of the 14th eCAADe Conference, Lund, Sweden, 12-14 September, ed. J. Klercker, 29-40.

- $\quad$ Anders, Peter. (2003). A procedural model for the integration of physical and cyberspaces in architecture. Doctoral thesis, University of Plymouth, U.K.

- $\quad$ Bjorkdah, Per. (1999). Implications and challenges facing the intelligent building industry.

Retrieved May 15, 2004 from: http://www.automatedbuildings.

com/news/sep99/articles/tacc/tacc.htm.

- $\quad$ Brodey, Warren. (1967). The design of intelligent environments: Soft architecture.

Landscape, Autumn, 8-12. Coen, Michael H. (1998). A prototype intelligent environment. In

Cooperative buildings: Integrating information, organization, and architecture, ed. Norbert A. Streitz, Shin'ichi Konomi, Heinz-Jürgen Burkhardt, 22-32. Berlin: Springer- Verlag.

- $\quad$ Coen, Michael H. (1998). A prototype intelligent environment. In Cooperative buildings: Integrating information, organization, and architecture, ed. Norbert A. Streitz, Shin'ichi Konomi, Heinz-Jürgen Burkhardt, 22-32. Berlin: Springer-Verlag.

- $\quad$ Fox, Michael A., \& Yeh, Bryant P. (1999). Intelligent kinetic systems in architecture. In Managing interactions in smart environments, ed. P. Nixon, S. Dobson, and G. Lacey, 91-

103. Berlin: Springer-Verlag.

- $\quad$ Hunt, Gillian. (1998). Architecture in the Cybernetic Age. Architectural Design 68(11-12): 5355.

Received: February 5, 2018

Accepted: April 2, 2018 